\title{
Understanding the decision to immunize: insights into the information needs and priorities of people who have utilized an online human papillomavirus (HPV) vaccine decision aid tool
}

\author{
Megan Highet $^{1}$ (D) $\cdot$ Geneviève Jessiman-Perreault $^{1}$ (D) $\cdot$ Emma Hilton $^{2}$ (D) Greg Law $^{1}$ (D) Lisa Allen-Scott $^{1,3,4}$ (D)
}

Received: 27 February 2020 / Accepted: 21 September 2020 / Published online: 19 October 2020

(C) The Canadian Public Health Association 2020

\begin{abstract}
Setting People in Alberta are more likely to seek information about cancer prevention online than they are to have this conversation with their primary care provider. As people turn to the internet to support health decision-making, it is critical that we improve the supportiveness of the virtual health setting for cancer prevention.

Intervention In 2014, the Alberta Cancer Prevention Legacy Fund launched an online HPV Decision Aid Tool to support evidence-informed decision-making in response to suboptimal uptake of the HPV (human papillomavirus) vaccine. Google Analytics data from approximately 2000 recent interactions with this tool have yielded insights into the concerns that impact people's decision-making about the vaccine.

Outcomes Most users of this tool are adults interested in the vaccine for themselves (69\%), rather than parents considering immunizing their children $(31 \%)$. No differences were found in the information-seeking behaviour of parents of girls compared with parents of boys, suggesting that mental models among those who are considering the HPV vaccine may have shifted in recent years. Concerns differed by respondent; cost was the most important concern among adults (62.0\%), while parents were most concerned about vaccine safety $(61.5 \%)$. Only $23 \%$ of users asked "what is HPV", suggesting that many people in Alberta now have basic knowledge about the virus.

Implications Results provide a real-time "pulse" on knowledge and attitudes towards HPV immunization, which informs our approach to tailoring messaging with the aim of increasing vaccine uptake in Alberta. Outcomes will provide evidence needed to inform new interventions aimed at increasing HPV immunization rates.
\end{abstract}

\section{Résumé}

Lieu Les gens de l'Alberta ont plus tendance à chercher des informations sur la prévention du cancer en ligne que d'en parler avec leur fournisseur de soins de premier recours. Comme les gens se tournent de plus en plus vers Internet pour éclairer leurs décisions en matière de santé, il est essentiel d'améliorer notre soutien aux milieux de soins virtuels de prévention du cancer. Intervention En 2014, le fonds spécial de l'Alberta pour la prévention du cancer (Alberta Cancer Prevention Legacy Fund) lançait un outil en ligne d'aide à la décision axé sur le VPH (virus du papillome humain) pour favoriser la prise de décisions éclairées par les données probantes, vu le recours sous-optimal au vaccin anti-VPH. Les données sur environ 2000 interactions récentes avec cet outil, extraites au moyen de Google Analytics, ont offert un aperçu des préoccupations qui comptent dans les décisions des gens au sujet du vaccin.

Résultats La plupart des utilisateurs de l'outil sont des adultes que le vaccin intéresse pour eux-mêmes (69 \%) plutôt que des parents qui songent à faire vacciner leurs enfants $(31 \%)$. Aucune différence n'a été constatée dans le comportement de recherche d'informations des parents de filles et des parents de garçons, ce qui indique que les modèles mentaux des personnes qui

Megan Highet

megan.highet@albertahealthservices.ca

Alberta Cancer Prevention Legacy Fund, Alberta Health Services, Holy Cross Centre, 22102 Street S.W., Calgary, Alberta T2S 3C3, Canada
2 Calgary, Canada

3 Department of Oncology, Cumming School of Medicine, University of Calgary, Calgary, Canada

4 Department of Community Health Sciences, Cumming School of Medicine, University of Calgary, Calgary, Canada 
envisagent le vaccin anti-VPH pourraient avoir changé ces dernières années. Les préoccupations différaient selon les répondants; le coût était la préoccupation la plus importante chez les adultes en général (62\%), tandis que les parents s'inquiétaient surtout de l'innocuité du vaccin $(61,5 \%)$. Seulement $23 \%$ des utilisateurs ont cherché « qu'est-ce que le VPH? », ce qui donne à penser que beaucoup de gens en Alberta ont maintenant des connaissances de base sur le virus.

Conséquences Nos résultats permettent de prendre le « pouls» en temps réel des connaissances et des attitudes à l'égard de l'immunisation contre le VPH, ce qui éclaire notre stratégie d'adaptation de nos messages en vue d'accroître le recours au vaccin en Alberta. Les résultats finaux fourniront les données probantes nécessaires pour éclairer de nouvelles interventions visant à accroître les taux d'immunisation contre le VPH.

Keywords HPV immunization · HPV vaccine · Cancer prevention · Decision aid tool · Evidence-informed decision-making · Virtual health setting

Mots-clés Immunisation contre le VPH · vaccin anti-VPH · prévention du cancer · outil d'aide à la décision · prise de décision éclairée par les données probantes $\cdot$ milieu de soins virtuel

\section{Introduction}

Human papillomavirus (HPV) is a leading cause of preventable cancers, yet experts agree that due to the HPV vaccine, cervical cancer is now nearly $100 \%$ preventable, while many more cases of anogenital, head, and neck cancers can also be avoided through increased immunization (Volesky et al. 2019). In Alberta, the HPV vaccine has been available at no direct cost to girls through the provincially funded, schoolbased immunization program, since 2008. In 2014, this program was expanded to include boys, and in July of 2020, eligibility under the provincial immunization program was finally extended to everyone up to and including the age of 26. Nevertheless, HPV vaccine coverage rates in Alberta remain below the $90 \%$ target rate. ${ }^{1}$

Despite a large body of evidence proving the safety and efficacy of HPV immunization, low immunization rates are often attributed to insufficient information to support decision-making (Chan et al. 2012), exposure to misinformation in online spaces that contributes to vaccine hesitancy (Madden et al. 2012), or structural barriers that are specific to the local context (Escoffery et al. 2019). There is therefore a need to examine factors that may function as barriers to HPV vaccine uptake to improve existing programs and inform new interventions that will support increased HPV immunization rates.

In August of 2014, the Alberta Cancer Prevention Legacy Fund $(\mathrm{ACPLF})^{2}$ launched our HPV Vaccine Decision Aid Tool (hereafter referred to as the Decision Aid), nested within our comprehensive cancer prevention website HealthierTogether.ca.

\footnotetext{
${ }^{1}$ Data source: Province-wide Immunization Program, AHS.

2 The ACPLF is an interdisciplinary cancer prevention and screening innovation unit housed within Alberta Health Services (AHS), which is the single provincial health authority in Alberta, Canada.
}

The Decision Aid was designed in collaboration with immunization, healthcare, and health marketing experts. It provides value-neutral, evidence-based information to support decision-making about HPV immunization among adults considering the vaccine for themselves, as well as parents considering the vaccine for their children. It has remained "live" on HealthierTogether.ca since launching and has had more than 13,000 unique visitors. In 2015, an internal evaluation of the Decision Aid found that it was effective given that approximately two thirds of visitors who were initially undecided about the HPV vaccine ended up making the decision to immunize against HPV after interacting with it.

While our Decision Aid continues to be one of the few examples of its kind online, it has recently begun serving an additional purpose. This paper will discuss how we have leveraged Google Analytics data collected through individual interactions with our Decision Aid to identify barriers to increasing HPV vaccine uptake in Alberta, and highlight the value of this information for informing new interventions aimed at increasing HPV vaccine uptake.

\section{Setting}

The online, or "virtual" setting is a key opportunity for public health innovation and intervention (Rice and Sara 2019), as people increasingly rely on online sources of health information (Tonsaker et al. 2014). This is particularly true in Alberta, where adults are now three times more likely to seek out information about cancer prevention online than they are to consider having this conversation with their primary care provider (Highet and EKOS 2019). As the onus for providing accurate, trustworthy, and reliable information about HPV immunization began to shift from health promotion in schools and public health clinics to virtual spaces, we identified a gap 
with regard to meeting the needs of people in Alberta who are looking to online sources for information about HPV immunization for cancer prevention. Our Decision Aid was therefore intended to meet people where they are at, in the virtual health setting. ${ }^{3}$

\section{Intervention}

Decision aids have been shown to be effective for engaging priority populations with unbiased information to support health decision-making (Rimer et al. 2004; Stacey et al. 2017). By improving knowledge, addressing misconceptions, and supporting a person's journey through the decisionmaking process, decision aids can be particularly effective for targeting those who are currently undecided about immunizing. It is within this undecided subpopulation where the greatest opportunity to increase HPV vaccine uptake exists (Leask 2011).

To support the development of our Decision Aid (hpvtool. healthiertogether.ca), our team undertook a critical literature review on parental decision-making and consulted with subject area experts on the risks and benefits associated with the HPV vaccine. These findings were integrated into the design of the Decision Aid in collaboration with an interdisciplinary team of applied public health researchers, healthcare providers, immunization experts, health marketers, and web designers.

At the beginning of the Decision Aid, visitors are asked whether they are considering the HPV vaccine for themselves, or for their child, and whether the individual is male or female. Based on these initial selections, the Decision Aid branches into different pathways that present tailored content. The visitor is then encouraged to select from a comprehensive list of topics that they may have questions or concerns about (see Table 1).

Since its launch, the Decision Aid has gone through three minor content updates (completed in 2017, 2019, and 2020) to reflect the most up-to-date information about access (the vaccine is now available free of charge in Alberta for those up to and including age 26), the immunization schedule (the vaccine is now administered through the school-based immunization program in grade 6 instead of grade 5), and medical guidelines (the number of doses required was reduced from 3 to 2 for most individuals). Although the Decision Aid was initially developed to address the information needs of people in Alberta, we recognized an opportunity to also leverage it as a source of near-real-time data that can be used to inform new innovations aimed at increasing HPV vaccine uptake in

\footnotetext{
${ }^{3}$ We acknowledge that in addition to website-based resources, social media plays a critical role in engaging people online. We are exploring this through other applied research projects.
}

Alberta. The analysis and discussion that follows highlights how insights drawn from the interactions of different groups of visitors to the Decision Aid have allowed us to identify the leading concerns and barriers to HPV immunization among visitors to this tool, which will subsequently be used to inform the design of new innovations aimed at increasing HPV vaccine uptake in Alberta.

\section{Methods}

Questions that we sought to answer through data collection and analysis were as follows: (1) Who was utilizing the Decision Aid during this period?; (2) What were the most frequent questions or concerns among different groups of visitors?; and (3) Did leading questions and concerns differ if the visitor was considering the vaccine for themselves or their child, or depending upon the sex of the intended recipient?

The period of data collection for this analysis spanned from the launch of the second version in February 2017 through to the end of the school year in June 2019. During this time, there were 3006 visits to the Decision Aid. Data collected from each visitor interaction included which questions and concerns about HPV each visitor selected, who the intended recipient of the vaccine was, and the sex of the intended recipient of the vaccine.

During data cleaning, two exclusions were made. We excluded several visitors who completed the Decision Aid multiple times, selecting all identity possibilities. We interpreted these as people who were testing different pathways through the tool, rather than seeking information for personal use. We also removed visitors who did not select any questions or concerns. This left us with a sample of 1995 visitors. Bivariate analyses using standardized mean difference were generated to test the strength of the difference in concerns and questions posed by different kinds of visitors to the Decision Aid. Given that differences found in the sample sizes between groups could confound the relationships under study, standardized mean difference scores (SD) are reported since SD are not impacted by sample size (Sullivan and Feinn 2012). Cohen (1988) proposed categorizing SD effect sizes as small (0.2), medium (0.5), or large (0.8) using his Effect Size Indices cut-offs. Therefore, SD are interpreted using these cut-offs. All statistical analyses were conducted using SAS Studio (version 3.6).

\section{Findings}

Table 1 presents the percent distribution of visitors according to the sex of the intended vaccine recipient, showing that the majority of the visitors were females considering the vaccine for themselves $(50.7 \%)$. Table 1 also presents the percent distribution of each HPV vaccine-related concern and question. The most frequently asked questions were "How much does it 
Table 1 Percent distribution of HPV vaccine decision tool potential vaccine user and selected concerns and questions $(n=1995)$

\begin{tabular}{ll}
\hline Variable & Percent (n) \\
\hline Potential vaccine user & \\
Female individual & $50.7 \%(1011)$ \\
Male individual & $18.3 \%(364)$ \\
Female child & $17.0 \%(339)$ \\
Male child & $14.1 \%(281)$ \\
Concerns and questions & \\
How much does it cost? & $50.5 \%(1017)$ \\
When should my son/my daughter/I be immunized? & $45.0 \%(904)$ \\
Does the HPV vaccine have side effects? & $43.8 \%(882)$ \\
Is the HPV vaccine safe? & $39.8 \%(802)$ \\
How does someone know they have HPV? & $36.2 \%(730)$ \\
What are the benefits associated with the HPV vaccine? & $36.9 \%(744)$ \\
What does HPV vaccine protect against? & $35.2 \%(710)$ \\
How many injections are required? & $34.4 \%(694)$ \\
Can HPV be treated? & $33.4 \%(663)$ \\
Can HPV be prevented without the vaccine? & $33.1 \%(668)$ \\
How common are HPV infections? & $32.0 \%(645)$ \\
What health problems does HPV cause? & $30.5 \%(615)$ \\
How does someone get HPV? & $30.4 \%(613)$ \\
What ingredients are in the HPV vaccine? & $29.7 \%(598)$ \\
What is HPV? & $23.3 \%(470)$ \\
Does getting the HPV vaccine encourage earlier sexual activity? & $15.1 \%(304)$ \\
Can my son/my daughter/I be immunized in school? & $12.9 \%(260)$ \\
\hline
\end{tabular}

cost?" (50.5\%), "When should my son/my daughter/I be immunized?" (45.0\%), and "Does the HPV vaccine have side effects?" (43.8\%).

Table 2 presents results from the SD analyses testing the strength of the difference in selected questions based on whether the visitor was considering the vaccine for themselves, or for their child. We found that questions selected differed based on the intended recipient of the vaccine. Parents were more likely to select a variety of questions that can broadly be categorized as relating to vaccine safety. Results from the SD analysis indicate medium differences on two such questions: "What ingredients are in the HPV vaccine?" (0.51) and "Is the HPV vaccine safe?" (0.66). On the other hand, individuals who were considering the vaccine for themselves were more likely to be concerned about the cost of the vaccine, with the question "How much does it cost?" displaying the strongest effect size in this study $(0.80)$. These results indicate that these groups have different questions and concerns with regard to immunization to protect against HPV.

Table 3 presents results from the SD analyses testing strength of the difference in questions and concerns selected by parents considering the HPV vaccine for their children based on whether the child is male or female. Interestingly, the sex of the child does not appear to have a significant impact on questions or concerns about the vaccine among parents, as the differences did not meet the threshold to be considered even a small effect $(\mathrm{SD}>0.2)$.

Table 4 presents findings from the SD analyses testing the strength of the difference in questions selected by individuals considering the vaccine for themselves based on their selfidentified sex. Once again, sex did not appear to have a significant impact on questions or concerns about the HPV vaccine given that the differences did not meet the threshold to be considered even a small effect $(\mathrm{SD}>0.2)$.

\section{Implications}

The results of this analysis indicate that there are important differences in the concerns about the HPV vaccine with regard to parents considering the vaccine for children, versus individuals considering the vaccine for themselves. While parents were more concerned about vaccine risks, safety, and side effects, they also selected more questions or concerns overall than did individuals considering the vaccine for themselves. This provides useful insights with regard to informing approaches to tailoring messaging intended to meet the information needs of this subpopulation. Specifically, this points to both a topical area of focus (vaccine safety) as well as a need to provide a broad range of detailed information in order to 
Table 2 Percent distribution of concerns and questions selected by HPV vaccine decision tool users by identity of vaccine recipient $(n=1995)$
Table 3 Percent distribution of concerns and questions selected by HPV vaccine decision tool users by sex of child $(n=620)$

\begin{tabular}{llll}
\hline Concerns and questions & \multicolumn{2}{l}{ Percent (95\% confidence interval) } & \multirow{2}{*}{$\begin{array}{l}\text { Standardized } \\
\text { difference }\end{array}$} \\
\cline { 2 - 3 } & Parent of child & Individual & \\
\hline How much does it cost? & $25.2 \%(21.7-28.6)$ & $62.0 \%(59.5-64.6)$ & 0.80 \\
Is the HPV vaccine safe? & $61.5 \%(57.6-65.3)$ & $30.2 \%(27.8-32.6)$ & 0.66 \\
What ingredients are in the HPV vaccine? & $45.7 \%(41.7-49.6)$ & $22.3 \%(20.1-24.5)$ & 0.51 \\
Does the HPV vaccine have side effects? & $57.7 \%(53.8-61.6)$ & $37.4 \%(34.8-39.9)$ & 0.42 \\
Does getting the HPV vaccine encourage & $24.4 \%(21.0-27.7)$ & $10.9 \%(9.3-12.6)$ & 0.36 \\
$\quad$ earlier sexual activity? & & & \\
Can my son/my daughter/I be immunized in & $19.8 \%(16.7-23.0)$ & $9.6 \%(8.0-11.2)$ & 0.29 \\
$\quad$ school? & & & \\
Can HPV be prevented without the vaccine? & $40.3 \%(36.5-44.2)$ & $29.9 \%(27.5-32.3)$ & 0.22 \\
What health problems does HPV cause? & $36.9 \%(33.1-40.8)$ & $27.5 \%(25.1-29.9)$ & 0.20 \\
What is HPV? & $27.7 \%(24.2-31.3)$ & $21.0 \%(18.9-23.2)$ & 0.16 \\
When should my son/my daughter/I be im- & $39.8 \%(36.0-43.7)$ & $47.6 \%(45.0-50.3)$ & 0.16 \\
$\quad$ munized? & $31.9 \%(28.3-35.6)$ & $39.1 \%(36.5-41.6)$ & 0.15 \\
How many injections are required? & $31.5 \%(27.8-35.1)$ & $38.3 \%(35.8-40.9)$ & 0.15 \\
How does someone know they have HPV? & $38.9 \%(35.0-42.7)$ & $32.4 \%(30.0-34.9)$ & 0.13 \\
What are the benefits associated with the HPV & & & \\
$\quad$ vaccine? & $35.7 \%(31.9-39.4)$ & $30.1 \%(27.7-32.5)$ & 0.12 \\
How common are HPV infections? & $31.5 \%(27.8-35.1)$ & $29.8 \%(27.3-32.2)$ & 0.04 \\
How does someone get HPV? & $35.8 \%(32.0-39.6)$ & $34.7 \%(32.2-37.2)$ & 0.02 \\
What does HPV vaccine protect against? & $32.6 \%(28.9-36.3)$ & $33.7 \%(31.2-36.2)$ & 0.02 \\
Can HPV be treated? & & & \\
\hline
\end{tabular}

\begin{tabular}{llll}
\hline Concerns and questions & Percent (95\% confidence interval) & \multirow{2}{*}{$\begin{array}{l}\text { Standardized } \\
\text { difference }\end{array}$} \\
\cline { 2 - 3 } & Female child & Male child & \\
\hline Is the HPV vaccine safe? & $65.2 \%(60.1-70.3)$ & $56.9 \%(51.1-62.8)$ & 0.17 \\
What ingredients are in the HPV vaccine? & $48.7 \%(43.3-54.0)$ & $42.0 \%(36.2-47.8)$ & 0.13 \\
What health problems does HPV cause? & $34.8 \%(29.7-39.9)$ & $39.5 \%(33.8-45.3)$ & 0.10 \\
Can HPV be prevented without the vaccine? & $41.9 \%(36.6-47.2)$ & $38.4 \%(32.7-44.2)$ & 0.07 \\
How common are HPV infections? & $34.2 \%(29.1-39.3)$ & $37.4 \%(31.7-43.1)$ & 0.07 \\
What are the benefits associated with the HPV & $41.3 \%(36.0-46.6)$ & $38.1 \%(32.4-43.8)$ & 0.07 \\
$\quad$ vaccine? & $33.6 \%(28.6-38.7)$ & $31.3 \%(25.9-36.8)$ & 0.05 \\
Can HPV be treated? & $34.8 \%(29.7-39.9)$ & $37.0 \%(31.3-42.7)$ & 0.05 \\
What does HPV vaccine protect against? & $37.8 \%(32.6-42.9)$ & $40.2 \%(34.4-46.0)$ & 0.05 \\
When should my son/my daughter be immu- & & & \\
$\quad$ nized? & $26.8 \%(22.1-31.6)$ & $28.8 \%(23.5-34.2)$ & 0.04 \\
What is HPV? & $23.6 \%(19.1-28.1)$ & $25.3 \%(20.2-30.4)$ & 0.04 \\
$\begin{array}{llll}\text { Does getting the HPV vaccine encourage } \\
\text { earlier sexual activity? }\end{array}$ & $25.7 \%(21.0-30.3)$ & $24.6 \%(19.5-29.6)$ & 0.03 \\
How much does it cost? & $31.9 \%(26.9-36.8)$ & $31.0 \%(25.5-36.4)$ & 0.02 \\
How does someone get HPV? & $31.0 \%(26.0-35.9)$ & $32.0 \%(26.5-37.5)$ & 0.02 \\
How does someone know they have HPV? & $57.2 \%(51.9-62.5)$ & $58.4 \%(52.6-64.2)$ & 0.02 \\
$\begin{array}{l}\text { Does the HPV vaccine have side effects? } \\
\text { Can my son/my daughter/I be immunized in }\end{array}$ & $19.5 \%(15.2-23.7)$ & $20.3 \%(15.6-25.0)$ & 0.02 \\
$\quad$ school? & $32.2 \%(27.2-37.2)$ & $31.7 \%(26.2-37.1)$ & 0.01 \\
\hline How many injections are required? & & & \\
\hline & & & \\
\hline
\end{tabular}


Table 4 Percent distribution of concerns and questions selected by HPV vaccine decision tool users by sex of individual $(n=1375)$

\begin{tabular}{llll}
\hline \multirow{2}{*}{ Concerns and questions } & \multicolumn{2}{l}{ Percent $(95 \%$ confidence interval) } & \multirow{2}{*}{$\begin{array}{l}\text { Standardized } \\
\text { difference }\end{array}$} \\
\cline { 2 - 3 } & Female individual & Male individual & \\
\hline What health problems does HPV cause? & $29.7 \%(26.9-32.5)$ & $21.4 \%(17.2-25.7)$ & 0.19 \\
Does the HPV vaccine have side effects? & $39.5 \%(36.5-42.5)$ & $31.6 \%(26.8-36.4)$ & 0.17 \\
Is the HPV vaccine safe? & $32.2 \%(29.3-35.0)$ & $24.7 \%(20.3-29.2)$ & 0.17 \\
When can I be immunized? & $49.9 \%(46.8-52.9)$ & $41.5 \%(36.4-46.6)$ & 0.17 \\
How does someone know they have HPV? & $40.3 \%(37.2-43.3)$ & $33.0 \%(28.1-37.8)$ & 0.15 \\
How does someone get HPV? & $31.4 \%(28.5-34.2)$ & $25.3 \%(20.8-29.8)$ & 0.14 \\
How common are HPV infections? & $31.8 \%(28.9-34.6)$ & $25.6 \%(21.1-30.1)$ & 0.14 \\
What ingredients are in the HPV vaccine? & $23.5 \%(20.9-26.2)$ & $19.0 \%(14.9-23.0)$ & 0.11 \\
What is HPV? & $21.9 \%(19.3-24.4)$ & $18.7 \%(14.7-22.7)$ & 0.08 \\
What are the benefits associated with the HPV & $33.3 \%(30.4-36.2)$ & $30.0 \%(25.2-34.7)$ & 0.07 \\
$\quad$ vaccine? & $38.2 \%(35.2-41.2)$ & $41.5 \%(36.4-46.6)$ & 0.07 \\
How many injections are required? & $30.7 \%(27.8-33.5)$ & $27.8 \%(23.1-32.4)$ & 0.06 \\
Can HPV be prevented without the vaccine? & $35.4 \%(32.5-38.4)$ & $32.7 \%(27.9-37.5)$ & 0.06 \\
What does HPV vaccine protect against? & $62.7 \%(59.7-65.7)$ & $60.2 \%(55.1-65.2)$ & 0.05 \\
How much does it cost? & $33.5 \%(30.6-36.5)$ & $34.1 \%(29.2-39.0)$ & 0.01 \\
Can HPV be treated? & $9.7 \%(7.9-11.5)$ & $9.3 \%(6.3-12.3)$ & 0.01 \\
Can my son/my daughter/I be immunized in & $10.9 \%(9.0-12.8)$ & $11.0 \%(7.8-14.2)$ & 0.004 \\
$\quad$ school? & & & \\
Does getting the HPV vaccine encourage & & & \\
$\quad$ earlier sexual activity? & & & \\
\hline
\end{tabular}

address all of the questions that parents have, which may impact their decision-making about immunizing their child against HPV.

Individuals seeking the vaccine for themselves appeared to be more concerned about the logistics of receiving the vaccine, particularly when it comes to cost. This suggests that rather than addressing HPV knowledge gaps, reducing structural barriers should be prioritized as a means for increasing HPV immunization rates among individuals aged 18-26. The finding (see Table 1) that only $23 \%$ of visitors selected the question "What is HPV" also suggests that many people in Alberta now have at least basic knowledge about the virus. Thus, while lack of knowledge may have been a significant barrier to HPV vaccine acceptance in the past (see Chan et al. 2012), this analysis reinforces the argument made elsewhere that adequate knowledge is only one piece of the puzzle when it comes to increasing HPV vaccine uptake. Although knowledge is a necessary precursor, improving attitudes towards HPV immunization is critical to this effort (Du et al. 2017; Shah et al. 2019; Sanawi et al. 2017). Consequently, insights from this study are already being used to inform new innovations within ACPLF that target influencing attitudes towards the HPV vaccine in the virtual setting. ${ }^{4}$

The fact that the sex did not have a significant impact on the type of concerns identified by visitors to the Decision Aid

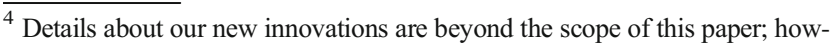
ever, they will be reported in future papers.
}

was unexpected given that a great deal of stigma and confusion is known to have followed from messaging associated with the HPV vaccine that initially only targeted girls (Lacombe-Duncan et al. 2018). The finding that sex is no longer a significant consideration among those who are considering the vaccine is evidence that activities aimed at addressing this public health issue have moved the needle on attitudes towards the vaccine that could otherwise have resulted in gender-based health inequities.

Now that the methodology for analyzing Google Analytics data from the Decision Aid has been tested, it will be feasible to repeat this research periodically in the future. This will be important for monitoring how prevailing questions and concerns about the HPV vaccine evolve in Alberta, particularly among individuals aged 18-26, now that eligibility to receive the vaccine at no direct cost to the individual has been extended up to and including the age of 26. This policy decision eliminated the most significant structural barrier to increasing vaccine uptake among this group; however, future research will be needed to explore the consequences of this on decision-making among adults who remain undecided about getting the HPV immunization. In the meantime, outcomes of this research will provide valuable insights for health marketing aimed at increasing awareness of the expanded accessibility to the vaccine for individuals aged 18-26 in Alberta.

Continuing to analyze Google Analytics data collected by our Decision Aid may also help to detect any changes in 
parental questions or concerns about the HPV vaccine, thereby serving as a quasi-early warning system that may be used to detect when events or media trigger an increase in mistrust or the spread of misinformation about HPV immunization (Du et al. 2017, 2019; Chakraborty et al. 2017; Shapiro et al. 2017).

\section{Strengths}

Local information generated by this analysis is necessary for informing and evaluating evidence-based policymaking, and for guiding the design of interventions aimed at building HPV vaccine confidence. While applied population health research is often time-intensive and costly to conduct, this study has demonstrated a lowcost approach for generating near-real-time insights that can serve as a "pulse" on public perceptions about provocative public health issues, such as HPV immunization. This approach also captures what information people in Alberta are actually interested in with regard to HPV immunization, rather than what they might have identified as an important consideration had the research questions been posed through a different research design (e.g., through questionnaires or key-informant interviews). This is important since we know what people say they do and what they actually do, are often not equivalent.

\section{Limitations}

There are several limitations in this study that warrant mention. First, approximately 1000 visits to the Decision Aid had to be removed from the dataset during data cleaning. Second, given the limited amount of demographic data available to us, we are unable to determine whether those who were excluded varied substantially from those included in the dataset, and we cannot speak to the generalizability of these data to the wider Alberta population. Third, as is typical with self-reported questionnaires, we are unable to determine whether individuals are answering truthfully, which could result in respondent bias. We assume, however, that since the tool provides tailored information, individuals are not wasting their own time by entering false information that would result in them not accessing the information that presumably motivated them to visit the tool. Fourth, it is possible that visitors to the Decision Aid are skewed towards higher socio-economic status groups who have easier access to the internet. Finally, given this tool is delivered through Alberta Health Services (AHS), our sample may include more individuals who trust AHS and seek out health information through governmental sources. Therefore, our sample may be subject to selfselection bias.

\section{Conclusion}

Both the Decision Aid and the findings generated from the data collected present opportunities to reduce barriers and build HPV vaccine confidence in Alberta. Our Decision Aid has proven effective for engaging priority populations and supporting them in making the decision to immunize against HPV, and it continues to attract thousands of visits each year. Google Analytics data collected through these visits will continue to provide valuable information that our innovation team will use to inform the design and delivery of interventions aimed at increasing HPV vaccine coverage rates for cancer prevention. While the largest barrier to increasing HPV vaccine uptake among adults has recently been eliminated through the expansion of the HPV vaccine eligibility criteria, our analysis has identified other areas that should be emphasized in future health marketing efforts. In particular, messaging aimed at building HPV vaccine confidence among parents should focus on vaccine safety, while messaging aimed at reducing gender-based stigma associated with the HPV vaccine may no longer be necessary in Alberta.

Ongoing analysis of Google Analytics data will inform a responsive approach for tailoring HPV messaging aimed at addressing the evolving needs and priorities of people in Alberta. This research also suggests that future efforts to increase HPV vaccine uptake in Alberta should focus more on attitudes towards the vaccine, rather than knowledge about HPV infection. In the post-COVID-19 world, as routine immunizations have been delayed or missed entirely, ${ }^{5}$ attention to maintaining progress made on HPV immunization for cancer prevention is all the more pertinent. By forming and maintaining partnerships across a variety of professions and health settings (but particularly the virtual health setting), we can help to ensure that the right information reaches people at the right time and place, and that it is delivered in the right way in order to sustain efforts aimed at reducing the burden of preventable cancers that are attributable to HPV infection.

Acknowledgements We would like to acknowledge the contributions of ACPLF colleagues who contributed to the design and evaluation of the HPV Vaccine Decision Aid Tool.

Authors' contributions All authors contributed to the study conception and design. Data were compiled by GL, GJP, and EH. Data cleaning was completed by EH and GJP. Data analysis was completed by GJP. Data interpretation was completed by MH, GJP, and LAS. The first draft of the manuscript was written by $\mathrm{MH}, \mathrm{GJP}$, and $\mathrm{EH}$. All authors provided input and feedback on subsequent versions of the manuscript. All authors read and approved the final manuscript.

Funding This research was funded by Alberta Health through the Alberta Cancer Prevention Legacy Fund (ACPLF). Provision of funding by Alberta Health does not signify that this project represents the policies

\footnotetext{
${ }_{5}^{5}$ See: https://www.who.int/immunization/monitoring_surveillance/ immunization-and-covid-19/en/
} 
or views of Alberta Health. The funders had no role in the design of the study; in the collection, analyses, or interpretation of data; in the writing of the manuscript; or in the decision to publish the results.

\section{Compliance with ethical standards}

A Project Ethics Community Consensus Initiative (ARECCI) Ethics Screening Tool assessment was completed for this project. The assessment determined that this analysis constitutes a quality improvement project. With a score of 2, the project was determined to pose minimal risk and should therefore be governed by ARECCI ethics guidelines for quality improvement and evaluation projects, rather than being submitted for review by a formal research ethics board.

Conflict of interest The authors declare that they have no conflict of interest.

\section{References}

Chakraborty, P., Colditz, J. B., Silvestre, A. J., Friedman, M. R., Bogen, K. W., \& Primack, B. A. (2017). Observation of public sentiment toward human papillomavirus vaccination on Twitter. Cogent Medicine, 4(1), 1390853.

Chan, Z. C., Chan, T. S., Ng, K. K., \& Wong, M. L. (2012). A systematic review of literature about women's knowledge and attitudes toward human papillomavirus (HPV) vaccination. Public Health Nursing, 29(6), 481-489.

Cohen, J. (1988). Statistical power analysis for the behavioral sciences (2nd ed.). Mahwah: Lawrence Erlbaum Associates Publishers.

Du, J., Xu, J., Song, H. Y., \& Tao, C. (2017). Leveraging machine learning-based approaches to assess human papillomavirus vaccination sentiment trends with Twitter data. BMC Medical Informatics and Decision Making, 17(2), 69.

Du, J., Luo, C., Shegog, R., Bian, J., Chen, Y., \& Tao, C. (2019). Deep learning and behavioral theory: An improved analytic method to understand HPV vaccination intentions from Twitter discussion. SSRN, 3460688.

Escoffery, C., Riehman, K., Watson, L., Priess, A., Borne, M., Halpin, S., Rhiness, C., Wiggins, E., \& Kegler, M. (2019). Peer reviewed: Facilitators and barriers to the implementation of the HPV VACs (vaccinate adolescents against cancers) program: A consolidated framework for implementation research analysis. Preventing Chronic Disease, 16(E85).

Highet, M., \& EKOS Research Associates (2019). Views on the Healthier Together website. Unpublished Research Report Prepared for the
Individuals \& Families Innovation Stream, Alberta Cancer Prevention Legacy Fund.

Lacombe-Duncan, A., Newman, P. A., \& Baiden, P. (2018). Human papillomavirus vaccine acceptability and decision-making among adolescent boys and parents: A meta-ethnography of qualitative studies. Vaccine, 36(19), 2545-2558.

Leask, J. (2011). Target the fence-sitters. Nature, 473(7348), 443-445.

Madden, K., Nan, X., Briones, R., \& Waks, L. (2012). Sorting through search results: A content analysis of HPV vaccine information online. Vaccine, 30(25), 3741-3746.

Rice, L., \& Sara, R. (2019). Updating the determinants of health model in the Information Age. Health Promotion International, 34(6), 12411249.

Rimer, B. K., Briss, P. A., Zeller, P. K., Chan, E. C., \& Woolf, S. H. (2004). Informed decision making: What is its role in cancer screening? Cancer: Interdisciplinary International Journal of the American Cancer Society, 101(S5), 1214-1228.

Sanawi, J. B., Samani, M. C., \& Taibi, M. (2017). \# vaccination: Identifying influencers in the vaccination discussion on twitter through social network visualisation. International Journal of Business and Society, 18(S4), 718-726.

Shah, Z., Surian, D., Dyda, A., Coiera, E., Mandl, K. D., \& Dunn, A. G. (2019). Automatically applying a credibility appraisal tool to track vaccination-related communications shared on social media. arXiv preprint arXiv:1903.07219.

Shapiro, G. K., Surian, D., Dunn, A. G., Perry, R., \& Kelaher, M. (2017). Comparing human papillomavirus vaccine concerns on Twitter: A cross-sectional study of users in Australia, Canada and the UK. BMJ Open, 7(10), e016869.

Stacey, D., Légaré, F., Lewis, K., Barry, M. J., Bennett, C. L., Eden, K. B., Holmes-Rovner, M., Llewellyn-Thomas, H., Lyddiatt, A., Thomson, R., \& Trevena, L. (2017). Decision aids for people facing health treatment or screening decisions. Cochrane Database of Systematic Reviews, (4).x.

Sullivan, G. M., \& Feinn, R. (2012). Using effect size - or why the P value is not enough. Journal of Graduate Medical Education, 4(3), 279-282.

Tonsaker, T., Bartlett, G., \& Trpkov, C. (2014). Health information on the Internet: Gold mine or minefield? Canadian Family Physician, 60(5), 407-408.

Volesky, K. D., El-Zein, M., Franco, E. L., Brenner, D. R., Friedenreich, C. M., Ruan, Y., \& ComPARe Study Team. (2019). Cancers attributable to infections in Canada. Preventive Medicine, 122, 109-117.

Publisher's note Springer Nature remains neutral with regard to jurisdictional claims in published maps and institutional affiliations. 